\title{
Modeling of Cu Direct Laser Drilling Process
}

\author{
Junichi OKADA $^{* 1}$, Yuuji OKAMOTO ${ }^{* 1}$, Kazumasa SHUDO ${ }^{* 1}$ and Masafumi YOROZU ${ }^{* 1}$ \\ ${ }^{* 1}$ Sumitomo Heavy Industries, Ltd. Mechanical System Engineering Dept. Research \& Development \\ Center, 19, Natsushima-cho, Yokosuka-shi, Kanagawa 237-8555, Japan \\ E-mail: Jnc_Okada@shi.co.jp
}

\begin{abstract}
Drilling of printed wiring boards (PWBs) by CO2 laser radiation was studied both experimentally and theoretically. Two types of processes are generally used for drilling: resin direct drilling (RDD) and $\mathrm{Cu}$ direct drilling (CDD). RDD is a single-layer removal process and is explained using the evaporative removal model under the condition that the laser pulse width exceeds a nanosecond. In this model, the processed material evaporates upon heating by a laser beam. In the CDD process, $\mathrm{Cu}$ and resin layers are simultaneously removed. However, $\mathrm{Cu}$ and resin have different physical characteristics. Therefore, the evaporative removal model cannot be applied to the CDD process, and a new model is required. An experimental study of CDD shows that via holes open at a certain irradiation energy. Thermal simulation revealed that the thermal decomposition of the resin interface is complete before copper is evaporated. These results show that as a result of thermal decomposition, resin's internal pressure increases rapidly and the pressure pushes upward the liquid $\mathrm{Cu}$ foil in the upper layer. Then, the vaporized resin scatters liquid copper. Furthermore, the via hole shape can be calculated using this model. DOI: $10.2961 / \mathrm{jlmn} .2012 .03 .0024$
\end{abstract}

Keywords: Laser drilling, Printed wiring board, $\mathrm{CO}_{2}$ laser, Heat transfer analysis, $\mathrm{Cu}$ direct drilling

\section{Introduction}

With the rapid spread and high performance of portable digital devices such as mobile phones, the use of multistratified printed wiring boards (PWBs) has become widespread. In a multistratified PWB, a via hole is processed to connect the upper layer with the lower layer by using wired connections. To drill this hole, high-speed processing is required. Therefore, laser drilling is widely used for via hole processing.

Two types of laser sources are used to drill PWBs: $\mathrm{CO}_{2}$ lasers (emission wavelength in the infrared region) and UV lasers. The $\mathrm{CO}_{2}$ laser process can drill faster than the UV laser process. For the reason that the $\mathrm{CO}_{2}$ laser is able to oscillate significant power, the $\mathrm{CO}_{2}$ laser process needs fewer pulse number than the UV laser process.

Fig. 1 shows the typical approach to $\mathrm{CO}_{2}$ laser drilling. In the preprocessing step, a window is formed in the outer $\mathrm{Cu}$ layer of a PWB by conformal and large window drilling processes to enable direct irradiation of the resin layer with the $\mathrm{CO}_{2}$ laser. The resin layer is composed of woven fiberglass cloth with an epoxy resin. To optimize the size, we consider the resin direct drilling (RDD) process, which follows a single-layer removal model.

In contrast, in $\mathrm{Cu}$ direct drilling (CDD), the outer $\mathrm{Cu}$ and resin layers are simultaneously removed, and a via hole is formed. This process is considered to follow the multilayer structure removal model.

In previous studies ${ }^{[1],[2]}$, the RDD model (including conformal and large window processes) was established. Furthermore, improvements in the shape of the via hole in the resin layer have been studied ${ }^{[3]}$. CDD has also been studied experimentally. However, there is no clear understanding of a detailed model of the process involved.
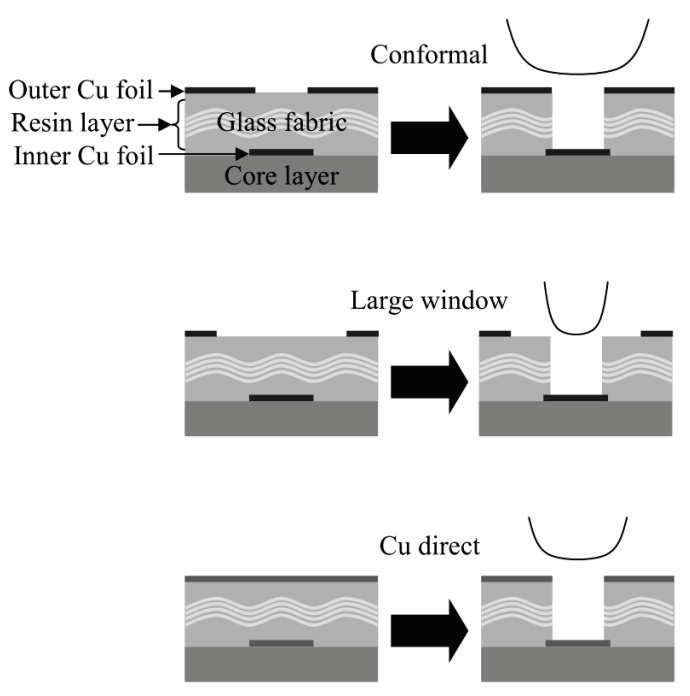

Fig. 1 Via hole drilling process

Therefore, this paper describes the mechanism of via hole formation by CDD.

\subsection{Resin direct drilling (RDD)}

The resin layer acts as an insulation layer between the outer and inner $\mathrm{Cu}$ layers and it primarily consists of an epoxy resin. To improve the strength of PWBs, FR-4 prepreg impregnated woven glass fabric is often used.

In conformal drilling, the open window diameter is usually equal to the via hole diameter, and the outer $\mathrm{Cu}$ foil acts as a masking material.

The large window drilling method uses a beam diameter that is almost $50-100 \mu \mathrm{m}$ smaller than the window diameter. 


\section{2 $\mathrm{Cu}$ direct drilling (CDD)}

In $\mathrm{CDD}$, the outer $\mathrm{Cu}$ layer is directly irradiated by a $\mathrm{CO}_{2}$ laser in the infrared range. However, infrared absorptance of an untreated $\mathrm{Cu}$ surface is very low (approximately $5 \%$ ). To solve this problem, surface treatment of the outer $\mathrm{Cu}$ layer is required. Possible treatments include black oxidation and various roughening processes. Surface treatment changes the outer $\mathrm{Cu}$ surface typically $12 \mu \mathrm{m}$ thick into an oxidized film approximately $2 \mu \mathrm{m}$ thick. This increases the surface infrared absorptance from $5 \%$ to $20 \%$ $70 \%$.

\section{Experimental method}

\subsection{Optical setup}

Fig.2 shows the optical setup of a $\mathrm{CO}_{2}$ laser drilling machine that has a control system for the spatial and temporal beam profiles.

The laser light source is a $\mathrm{CO}_{2}$ laser with a wavelength of $9.3 \mathrm{um}$, laser pulse width is $2-800 \mathrm{us}$, and average power is more than $280 \mathrm{~W}$. The spatial beam profile at the working surface can be controlled by the use of various optical systems. Variable beam shaper in Fig.2 has a telecentric optical system with aspheric lens. This optical setup results in optical transcription from the mask surface to the working surface.

Fig. 3 shows the spatial beam profile of each surface. The temporal beam profile is a square wave, and the pulse width is controllable.

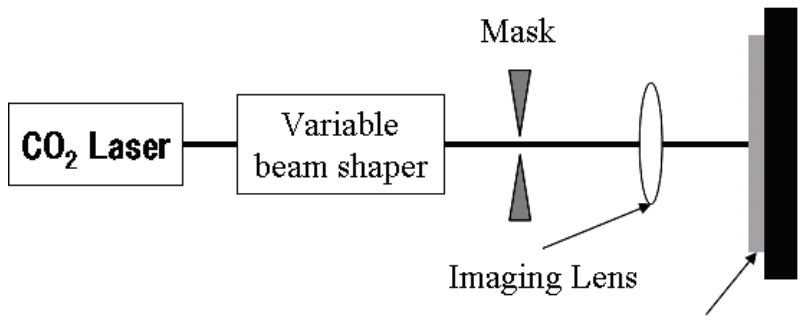

Working Surface

Fig. 2 Optical setup of $\mathrm{CO}_{2}$ laser drilling machine involving laser source, mask surface, and working surface

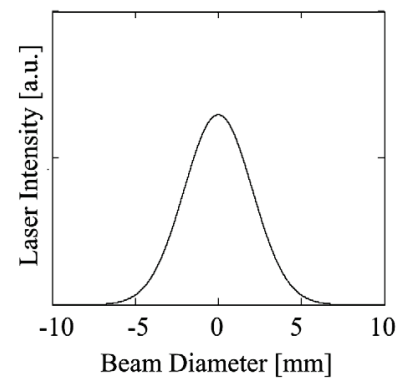

(a) Laser

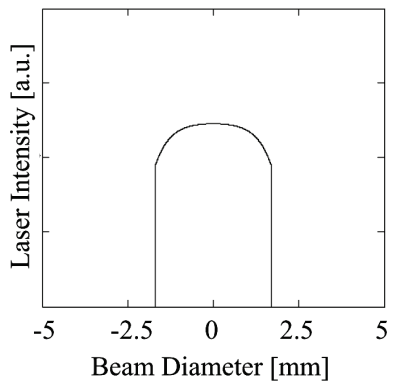

(b) Mask

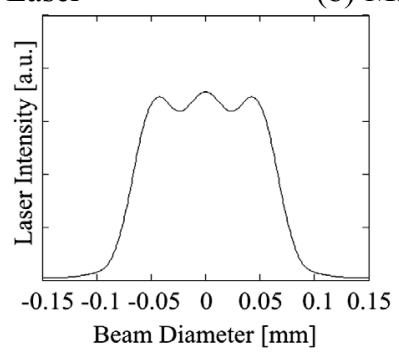

(c) Working surface

\subsection{Experimentally determined relationship between irradiation energy and hole shape}

The drilling properties of RDD and CDD were compared. Table 1 lists the experimental conditions. The irradiation energy can be controlled by varying the pulse width. The material used in RDD does not have an outer $\mathrm{Cu}$ layer, whereas the CDD material is covered by a black oxide film (thickness: $2 \mu \mathrm{m}$, surface infrared absorptance: $25 \%$ ).

Fig. 4 shows the relationship between irradiation energy and hole diameter. The hole diameter in case of RDD processing increases with the irradiation energy. However, in case of CDD processing, a certain energy threshold range $(4.2-6.6 \mathrm{~mJ})$ must be reached to penetrate the outer $\mathrm{Cu}$ layer. If the irradiation energy is larger than $6.6 \mathrm{~mJ}$, the hole diameter is unchanged.

Table 1 Experimental conditions

\begin{tabular}{|c|c|c|}
\hline \multicolumn{3}{|c|}{ Material conditions } \\
\hline Type & Resin direct & Cu direct \\
\hline $\mathrm{Cu}$ thickness & & $12 \mu \mathrm{m}$ \\
\hline Resin thickness & $55 \mu \mathrm{m}$ & $60 \mu \mathrm{m}$ \\
\hline \multicolumn{3}{|c|}{ Laser conditions } \\
\hline Beam diameter & $160 \mu \mathrm{m}$ & $160 \mu \mathrm{m}$ \\
\hline Spatial beam profile & Flat top & Flat top \\
\hline Temporal beam profile & Square & Square \\
\hline Irradiation energy & $1.1-8.7 \mathrm{~mJ}$ & $1.0-11.5 \mathrm{~mJ}$ \\
\hline
\end{tabular}

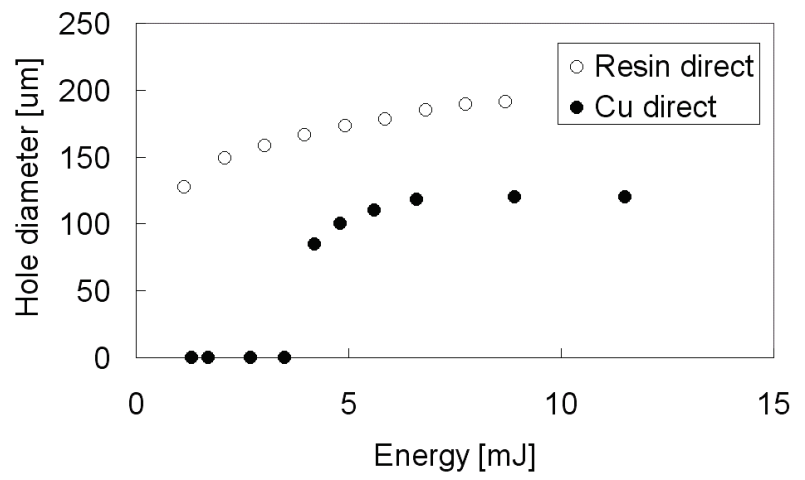

Fig. 4 Relationship between irradiation energy and hole diameter

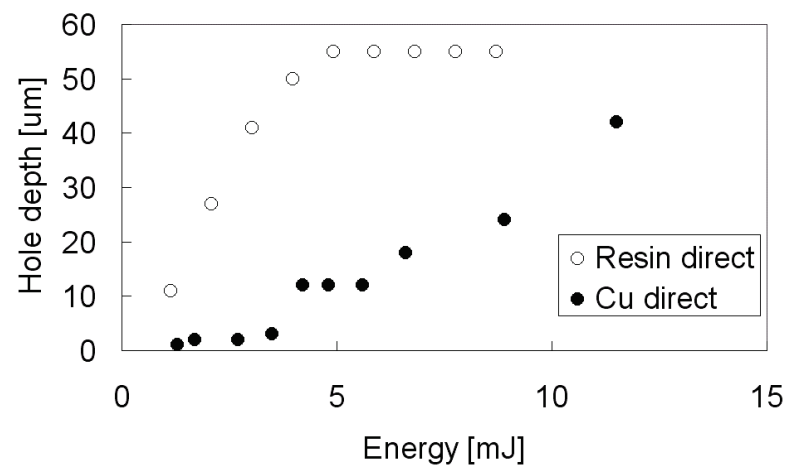

Fig. 5 Relationship between irradiation energy and hole depth

Fig. 3 Spatial beam profile control 


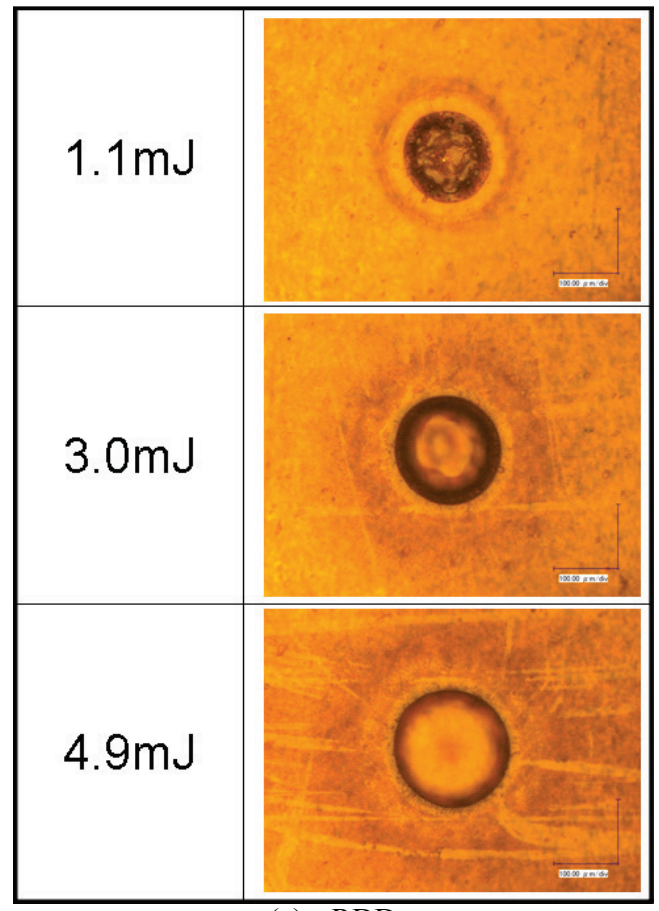

(a) RDD

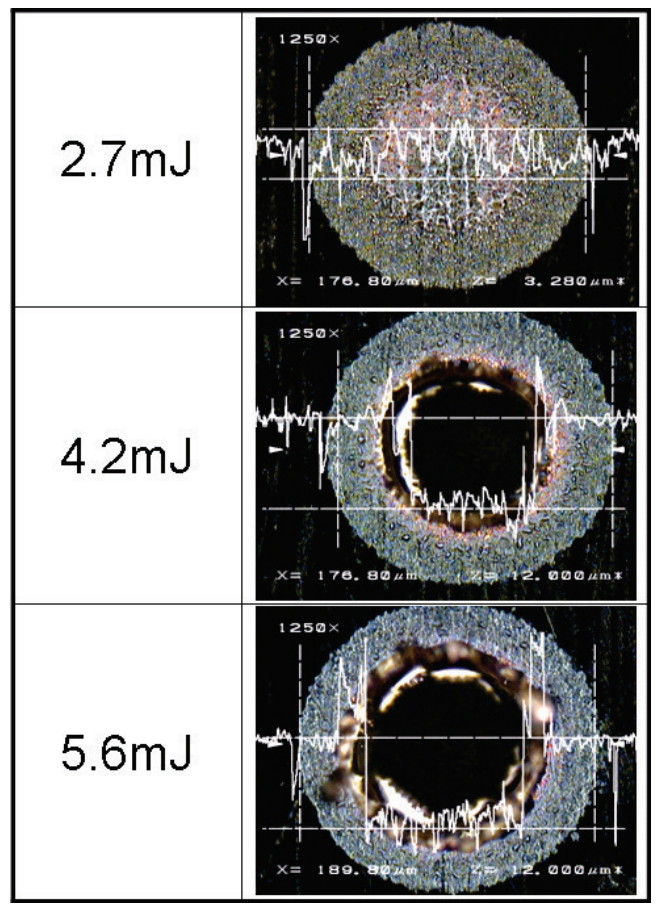

(b) CDD

Fig. 6 Top views of via hole

Fig. 5 shows the relationship between irradiation energy and hole depth. The graph of the hole depth in CDD exhibits a plateau at an energy of 4.2-5.6 $\mathrm{mJ}$ and a hole depth of $12 \mu \mathrm{m}$. This indicates that drilling of the resin layer is not observed when the energy is sufficiently high to pass through the outer $\mathrm{Cu}$ layer.

Fig.6 shows top views of the via holes. In CDD, the scattered $\mathrm{Cu}$ foil does not appear to be vaporized.

\section{Process simulation}

\subsection{Flow chart}

The purpose of this process simulation is to determine the shape of the via hole. Fig. 7 shows a flow chart of the method. The simulation is divided into the following two calculation stages:

1) Simulation of light propagation considering diffraction

2) Solving the heat equation to determine the state of each layer

The method of optical simulation with light propagation considering diffraction is explained in [4]. The simulation results are shown in Fig. 3(c).

We measure the experimental spatial beam profile of the working surface by using the shape of the laser-drilled hole of a polyimide film. Polyimide film exhibits a spatial beam profile. This result agrees with the experimental spatial beam profile of the working surface.

In Section 3.3, we explain the method of solving the heat equation (2D unsteady conduction analysis with the finite difference method, FDM) to determine the state of each layer.

After the decision state (solid/liquid/vapor/pyrolysis gas), this simulation determines whether ablation was complete for each mesh and it generally uses the evaporative removal model ${ }^{[5]}$. For this model to be applicable, the laser pulse width must exceed $1 \mathrm{~ns}$, and the laser emission wavelength must be in the visible to infrared range. Therefore, the $\mathrm{CO} 2$ laser drilling process was considered to follow this model.

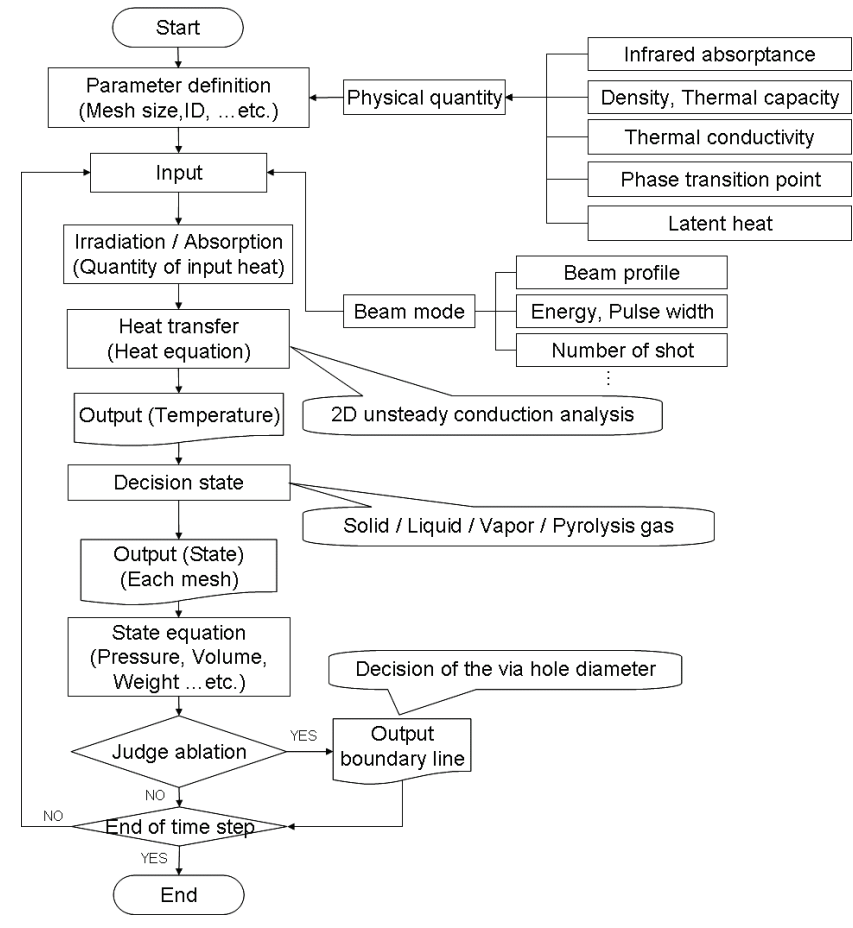

Fig. 7 Flow chart of drilling process simulation 


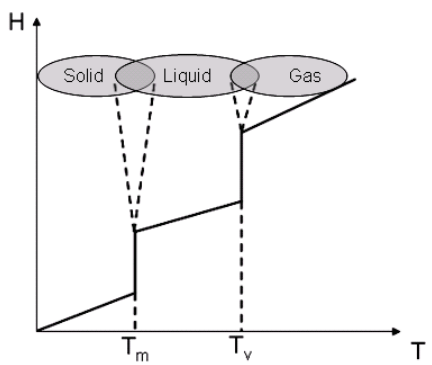

(a)

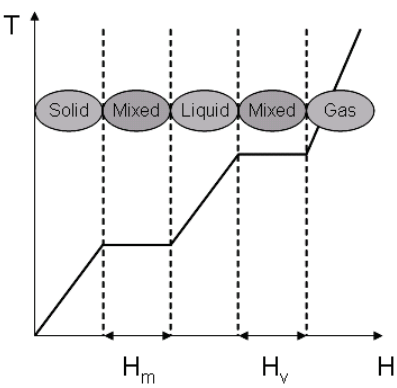

(b)
Fig. 8 State diagram

\subsection{Input parameters}

Actual measurement values were used for the thermal properties of each PWB material. Typical physical characteristics of the materials are shown in Table 2.

Note that the absorptance of the treated $\mathrm{Cu}$ surface $(\mathrm{CuO})$ differs for each PWB. To correctly measure absorptance, we selected an infrared thermography technique reported in an earlier study ${ }^{[6]}$.

The decomposition heat of each epoxy resin also differs for each PCB. We selected a technique that uses thermogravimetric analysis-differential scanning calorimetry (TGA-DSC). TGA determines changes in the weight of a sample relative to temperature. DSC is a thermoanalytical technique in which the difference in the amount of heat required to increase the temperature of a sample and that of a reference is measured as a function of temperature.

Total heat absorption obtained by TGA-DSC is then translated into the latent heat of decomposition.

\subsection{Heat equation}

The 2D heat transfer equation for an axisymmetric model is given by

$$
\rho \cdot C_{p} \frac{\partial T}{\partial t}=\frac{1}{r} \frac{\partial}{\partial r}\left\{\kappa\left(r \frac{\partial T}{\partial r}\right)\right\}+\frac{\partial}{\partial z}\left\{\kappa\left(\frac{\partial T}{\partial z}\right)\right\}+Q(1)
$$

where, $T$ is the temperature, $\rho$ is the density, $C_{p}$ is the thermal capacity, $\kappa$ is the thermal conductivity, and $Q$ is the quantity of the heat input. This quantity is considered as the source term, which is given by

$$
Q=\alpha(1-R) I_{0}(t) F(r)
$$

where, $\alpha$ is the absorption coefficient, $R$ is the reflectance, $I_{0}$ is the time-dependent intensity of the pulse light, and $F(r)$ is the spatial beam profile of the working surface. This spatial beam profile is given by the simulation of light propagation considering diffraction, as shown in Fig.3(c).

When phase transitions occur, the effect of latent heat must be considered to solve the heat equation. The effect of latent heat is shown in the state diagram in Fig.8(a). At the melting point temperature, the material can be either solid, liquid, or a mixture of both.

We begin to reformulate the heat equation by defining the total change in enthalpy, as given in equation (3).

\begin{tabular}{|c|c|c|c|}
\hline Material & $\mathrm{Cu}$ & $\mathrm{CuO}$ & $\begin{array}{l}\text { Epoxy } \\
\text { resin }\end{array}$ \\
\hline Density $\left[\mathrm{g} / \mathrm{cm}^{3}\right]$ & 8.95 & 6.76 & 1.72 \\
\hline Specific heat $[\mathrm{J} / \mathrm{gK}]$ & 0.39 & 0.53 & 0.95 \\
\hline $\begin{array}{c}\text { Thermal conductivity } \\
{[\mathrm{W} / \mathrm{cm} \cdot \mathrm{K}]}\end{array}$ & 4.01 & 0.032 & 0.003 \\
\hline $\begin{array}{c}\text { Infrared } \\
\text { absorptance }\end{array}$ & 0.05 & $\begin{array}{l}0.2-0.7 \\
(0.25)\end{array}$ & 0.8 \\
\hline $\begin{array}{l}\text { Melting temp. [K] } \\
\text { (Decomposition) }\end{array}$ & 1357 & 1474 & $\begin{array}{l}(370- \\
1200)\end{array}$ \\
\hline $\begin{array}{l}\text { Heat of melting }[\mathrm{J} / \mathrm{g}] \\
\text { (Decomposition) }\end{array}$ & 209 & 148 & $(807.9)$ \\
\hline $\begin{array}{c}\text { Absorption coefficient } \\
{[1 / \mathrm{cm}]}\end{array}$ & $\begin{array}{c}7.7 \\
\times 10^{5} \\
\end{array}$ & $\begin{array}{c}7.14-7.7 \\
\times 10^{5} \\
\end{array}$ & $\begin{array}{r}1.0 \\
\times 10^{4} \\
\end{array}$ \\
\hline Evaporation temp. [K] & 2840 & & \\
\hline
\end{tabular}

Table 2 Typical physical characteristics of the materials

$\Delta H(T)=\int_{T_{0}}^{T} \rho C_{p} d T+\xi\left(T-T_{m}\right) H_{\text {latent }, m}+\eta\left(T-T_{v}\right) H_{\text {latent }, v}$

$\xi(x)=\left\{\begin{array}{l}1 \text { when } x>0 \\ 0 \text { otherwise }\end{array}\right.$

$\eta(y)=\left\{\begin{array}{l}1 \text { when } y>0 \\ 0 \text { otherwise }\end{array}\right.$

The integrand describes the heat input required to heat the solid to a temperature $\mathrm{T}$, and the Heaviside function $\left[\xi\left(T-T_{m}\right)\right]$ switches on the latent heat when the temperature exceeds the melting temperature $\left(T_{m}\right)$. Partial differentiation of both sides of equation (3) gives

$$
\frac{\partial H}{\partial t}=\rho C_{p} \frac{\partial T}{\partial t}
$$

Substitution into equation (1) produces the enthalpy based heat equation below.

$$
\frac{\partial H}{\partial t}=\frac{1}{r} \frac{\partial}{\partial r}\left\{\kappa\left(r \frac{\partial T}{\partial r}\right)\right\}+\frac{\partial}{\partial z}\left\{\kappa\left(\frac{\partial T}{\partial z}\right)\right\}+Q
$$

This equation produces the state diagram shown in Fig.8(b), which is a one-to-one relationship between enthalpy and the separated state. Based on our simulation, equation (5) is translated into a difference formula.

\subsection{Simulation results}

The simulated relationships between irradiation energy and hole diameter are shown in Fig. 9. The experimental results (RDD: $\bigcirc$, CDD: 0 ) are shown for comparison with the simulation results (RDD: dashed line, CDD: solid line).The experimental and simulation results agree well in case of RDD. However, in case of CDD, a significant discrepancy is observed between these results. The experimental result for CDD shows that approximately $5 \mathrm{~mJ}$ of irradiation energy is needed to penetrate the $\mathrm{Cu}$ layer, whereas the simulation result for CDD shows that approximately $20 \mathrm{~mJ}$ of irradiation energy is necessary to evaporate the $\mathrm{Cu}$ layer. These results show that it is impossible to apply the evaporative removal model for CDD. Therefore, a new model is required. 


\subsection{Thermal analysis of CDD}

To determine the decision state and time change of state, we performed thermal analysis of each CDD layer at the central beam axis. We analyzed the CDD material described in Table 1 with the following conditions: (1) thickness of materials: $\mathrm{CuO}: 2 \mu \mathrm{m}, \mathrm{Cu}: 10 \mu \mathrm{m}$, epoxy resin: 60 $\mu \mathrm{m}$; (2) laser conditions: irradiation energy: $11.5 \mathrm{~mJ}$, irradiation time: $15 \mu \mathrm{s}$; and (3) end of time step: $20 \mu \mathrm{s}$. The result is shown in Fig. 10.

Fig. 10 shows the phase transition temperature at the central beam axis of each layer calculated numerically by FDM. In Fig. 10, $(\diamond)$ denotes the temperature $0.25 \mu \mathrm{m}$ below the top surface, $(\triangle)$ denotes the temperature of the interface between $\mathrm{CuO}$ and $\mathrm{Cu},(\mathrm{O})$ denotes the temperature of the interface between $\mathrm{Cu}$ and the resin, and $(\mathrm{O})$ denotes the temperature $0.25 \mu \mathrm{m}$ below the $\mathrm{Cu} / \mathrm{resin}$ interface. According to this result, the temperature of the surface layer, which consists of $\mathrm{CuO}$, increases rapidly and the layer reaches the vapor phase. The top and bottom of the $\mathrm{CuO}$ layer are vaporized in approximately 1 and $10 \mu \mathrm{s}$, respectively. During this time, the heat is transferred from the $\mathrm{CuO}$ layer to the untreated $\mathrm{Cu}$ layer. The top and bottom $\mathrm{Cu}$ layers reach the melting point $(1357 \mathrm{~K}$ : solid line) after 7 and $12 \mu \mathrm{s}$, respectively. Although the $\mathrm{Cu}$ layer does not reach the vaporization point $(2840 \mathrm{~K})$, the resin layer under the liquid phase of $\mathrm{Cu}$ reaches the decomposition point $(1200 \mathrm{~K})$ after $12 \mu \mathrm{s}$ owing to thermal conduction.

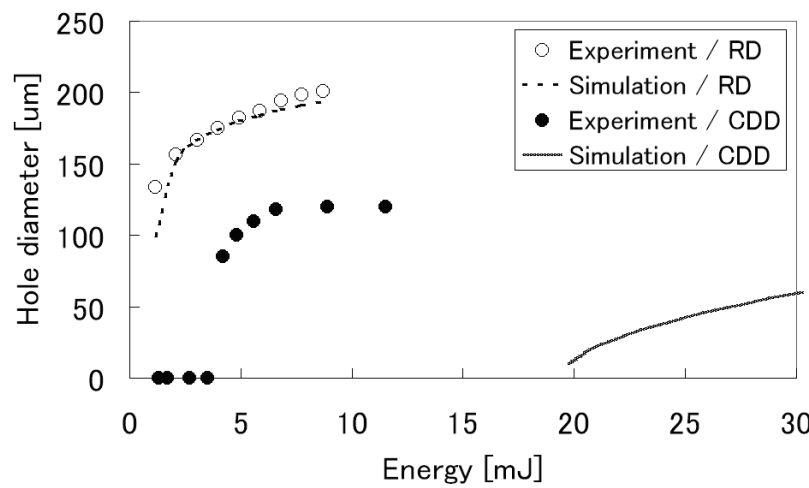

Fig. 9 Result of simulation using the evaporative removal model

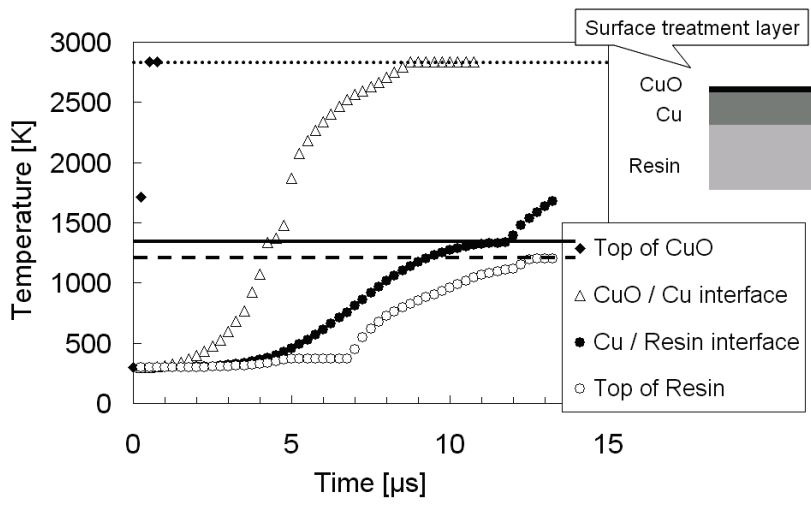

Fig. 10 Relationships between laser irradiation time and temperature for each layer

\section{Discussion}

\subsection{Theoretical model}

The experimental results for the CDD process show that the via hole opens at a certain irradiation energy, and the energy required to penetrate the outer $\mathrm{Cu}$ layer is approximately one-quarter of that necessary for evaporation of the $\mathrm{Cu}$ layer. Thermal analysis of the CDD process shows that thermal decomposition of the resin interface is complete before $\mathrm{Cu}$ is evaporated. These results suggest a new model, which is shown in Fig. 11. Owing to thermal conduction in the $\mathrm{Cu}$ layer, the rapid increase in the internal gas pressure of the resin can scatter liquid $\mathrm{Cu}$ and create a via hole. In this model, the area of liquid $\mathrm{Cu}$ area and the via hole are the same at the instant liquid $\mathrm{Cu}$ is scattered. Scattering releases the pressure between the resin and the $\mathrm{Cu}$ layers. Therefore, we can consider that the subsequent drilling process follows the evaporative removal model. The time of liquid $\mathrm{Cu}$ scattering is that at which the internal pressure of the resin is sufficient to increase the total weight of the liquid copper. We treat this model as the CDD model.

\subsection{Simulation with CDD model}

We adapted this CDD model to the process simulation of Fig. 7. The experimental and simulation results with this model are compared in Fig. 12.

Fig. 12(a) shows the relationship between irradiation energy and hole diameter. The simulation result is consistent with the experimentally measured data, and the threshold energy, which was significantly higher for the evaporative removal model, agrees with the experimentally measured one. However, there is still a difference of approximately $4 \mathrm{~mJ}$ between the model and experimental results. This is believed to be caused by the influence of glass fabric in the epoxy resin layer and scattering light at the interface between the $\mathrm{CuO}$ and $\mathrm{Cu}$ layers.

Fig. 12(b) shows the relationship between irradiation energy and hole depth. The experimental and simulation results both exhibit a plateau in the graph. If the required time for $\mathrm{Cu}$ scattering is longer than the pulse width, the laser beam cannot be used to directly drill the resin layer. Furthermore, experimental and simulation results of hole depth vary. It is thought that this difference is caused by the influence of the glass fabric in the epoxy resin layer because a significant difference is observed after liquid copper scattering.

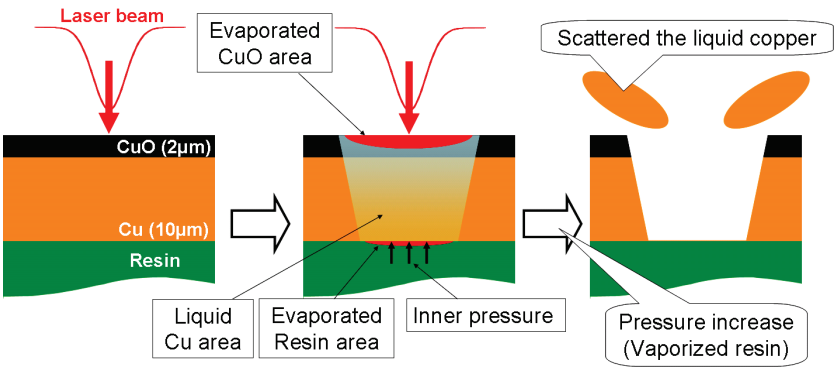

Fig. 11 Model of CDD 


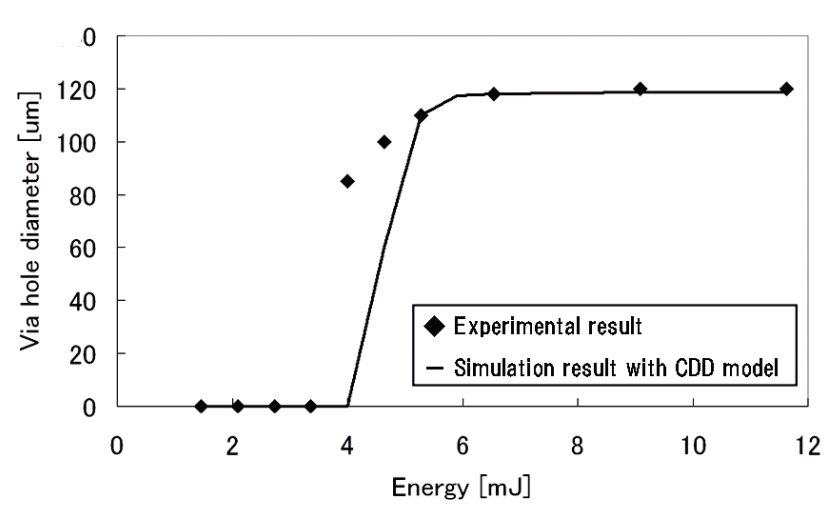

(a) Hole diameter

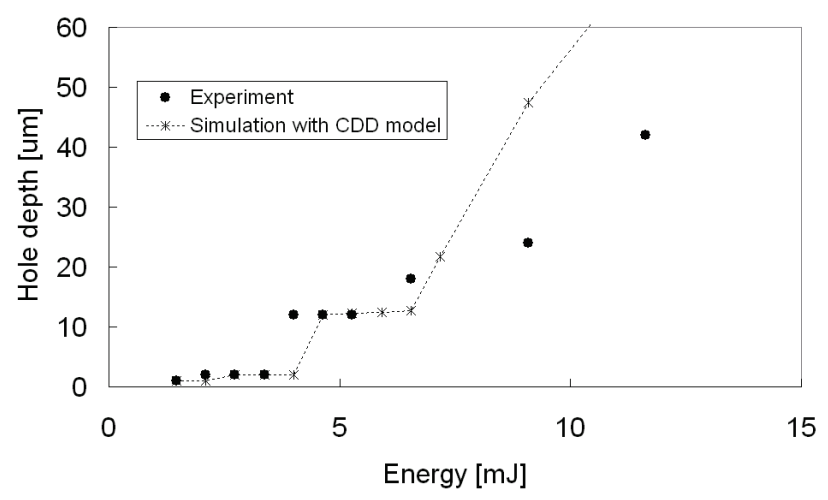

(b) Hole depth

Fig. 12 Simulation results with CDD model

\section{Conclusion}

By comparing the experimental and simulation results of the laser drilling process, we developed a CDD model with the following characteristics.

1) The single-layer removal process is described by the evaporative removal model.

2) In the model showing via hole formation with the $\mathrm{CDD}$ process, the area in which liquid $\mathrm{Cu}$ exists has the shape of the via hole before the liquid $\mathrm{Cu}$ foil is scattered.

3) The existence of a certain energy threshold is explained by the timing of liquid $\mathrm{Cu}$ scattering.

Using this new CDD model, we can present an approximate analysis of the via hole shape by using $\mathrm{Cu}$ direct laser drilling, and we can find the optimum laser irradiation condition. This model can also describe the laser drilled via hole shape of PCBs with treated and untreated $\mathrm{Cu}$ surfaces.

\section{References}

[1] S. Noguchi, E. Ohmura, and I. Miyamoto: Journal of the Japan Society for Precision Engineering Papers, 69, (4), 536-541, (2003) in Japanese

[2] T. Hirogaki, E. Aoyama, K. Ogawa, R. Minagi, T. Murakami and N. Doi: Journal of the Society of Materials Science Japan, 55, (3), 335-340, (2006) in Japanese

[3] C. J. Moorhouse, F. Villarreal, J. J. Wendland, H. J. Baker, D.R. Hall and D.P. Hand: Proc. of SPIE, 276283, (2004)
[4] S. Noguchi and E. Ohmura: Journal of the Japan Society for Precision Engineering Papers, 71, (10), 12961302, (2005) in Japanese

[5] D. Bauerle: "Laser Processing and chemistry" ed. by Springer-Verlag Berlin Heidelberg New York (Publisher, Germany, 1996) p.173. (Books)

[6] T. Hirogaki, E. Aoyama, K. Ogawa, S. Matsutani and T. Ayuzawa: Transactions of the Japan Society of Mechanical Engineers. C 76(771), 3143-3149, (2011) in Japanese

(Received: June 10, 2011, Accepted: October 18, 2012) 